\title{
Two New Eudesmane Sesquiterpenoids from the Flowers of Chrysanthemum indicum
}

\author{
Jun-Li Yang ${ }^{1} \cdot$ Lei-Lei Liu ${ }^{1} \cdot$ Yan-Ping Shi ${ }^{1}$
}

Received: 4 January 2019 / Accepted: 20 February 2019 / Published online: 28 February 2019

(c) The Author(s) 2019

\begin{abstract}
The flowers of Chrysanthemum indicum, i.e. Ye-ju-hua recorded in the Chinese Pharmacopoeia, has been widely used in China as an important heat-clearing and detoxifying herb for the treatment of inflammation, headache, and vertigo. A phytochemical investigation of this herb has led to the isolation of two new eudesmane sesquiterpenoids, 7-epi-eudesm4(15),11(13)-diene-1 $\beta, 3 \beta$-diol (1) and 7-epi-1 $\beta$-hydroxy- $\beta$-eudesmol (2). The molecular structures of these new sesquiterpenoids were established based on the comprehensive spectroscopic analyses, including NMR, MS, and IR, and comparing with the literatures.
\end{abstract}

\section{Graphical Abstract}
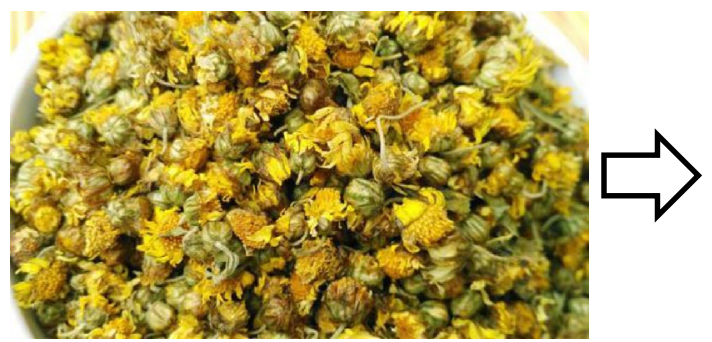<smiles>C=C(C)[C@H]1CC[C@@H]2C(=C)[C@@H](O)C[C@@H](O)[C@H]2C1</smiles>

1<smiles>C=C1CC[C@@H](O)[C@]2(C)CC[C@H](C(C)(C)O)C[C@@H]12</smiles>

2

Flowers of Chrysanthemum indicum (野菊花)

Keywords Chrysanthemum indicum · Sesquiterpenoids · Eudesmane

\section{Introduction}

Electronic supplementary material The online version of this article (https://doi.org/10.1007/s13659-019-0199-9) contains supplementary material, which is available to authorized users.

\section{Yan-Ping Shi}

shiyp@licp.cas.cn

1 CAS Key Laboratory of Chemistry of Northwestern Plant Resources and Key Laboratory for Natural Medicine of Gansu Province, Lanzhou Institute of Chemical Physics, Chinese Academy of Sciences, Lanzhou 730000, People's Republic of China
The plants of Asteraceae family, which contains 25 000-30 000 species belonging to over 1000 genera, have been considered as rich sources of eudesmane sesquiterpenoids [1]. Till now there have been over 1000 naturally occurring eudesmane sesquiterpenoids identified from the Asteraceae family, and these plant metabolites possessed diverse oxygenation and cleavage patterns [2]. Eudesmane-type sesquiterpenoids exhibit a wide range of biological activities, such as plant growth regulating, insect antifeedant, antifungal, anti-tumour, antibacterial, and antiviral activities [3-11]. Due to these, eudesmane-type sesquiterpenoids 
have long been the research focus of the phytochemists and pharmacologists.

The flowers of Chrysanthemum indicum has long been used a traditional heat-clearing and detoxifying herb in China. It is called Ye-ju-hua in the Chinese Pharmacopoeia [12]. The main usage of this traditional Chinese medicine was to treat inflammation, headache, and vertigo and for the preparation of a bitter tea used for antibacterial, antioxidant, and anti-inflammatory purposes [13]. It has long been our goal to find more novel sesquiterpenoids from traditional Chinese herbs [14-18]. As part of this program, an investigation of an aqueous EtOH extract of the flowers of $C$. indicum afforded 2 further new sesquiterpenoids (Fig. 1), 7-epi-eudesm-4(15),11(13)-diene-1 $\beta, 3 \beta$-diol (1) and 7-epi$1 \beta$-hydroxy- $\beta$-eudesmol (2). In this paper we will report the procedures for the isolation and structure determination of the two new isolates.

\section{Results and Discussion}

Sesquiterpenoid 1 was isolated as a white solid with a optical rotation value of $[\alpha]_{\mathrm{D}}^{20}+5.0$ ( $c 0.2$, acetone), which suggested this compound could be a racemate. It was assigned a molecular formula of $\mathrm{C}_{15} \mathrm{H}_{24} \mathrm{O}_{2}$ as determined based on an ion peak at $m / z 219.1750\left[\mathrm{M}-\mathrm{H}_{2} \mathrm{O}+\mathrm{H}\right]^{+}\left(\right.$calcd for $\mathrm{C}_{15} \mathrm{H}_{23} \mathrm{O}$, 219.1743) in its positive HRESIMS, which suggested four degrees of unsaturation. The IR absorptions at 3384 and $1654 \mathrm{~cm}^{-1}$ suggested the presence of hydroxy and olefinic functionalities, respectively. The ${ }^{1} \mathrm{H}$ and ${ }^{13} \mathrm{C}$ NMR data of 1 revealed (Table 1$)$ an angular methyl $\left(\delta_{\mathrm{H}} 0.74, \delta_{\mathrm{C}} 9.9\right)$, a vinyl methyl $\left(\delta_{\mathrm{H}} 1.70, \delta_{\mathrm{C}} 22.2\right)$, two oxymethines $\left(\delta_{\mathrm{H}} 3.44\right.$, $\left.\delta_{\mathrm{C}} 77.1 ; \delta_{\mathrm{H}} 4.06, \delta_{\mathrm{C}} 70.4\right)$, and two terminal double bonds $\left(\delta_{\mathrm{H}}\right.$ $\left.4.73,5.11, \delta_{\mathrm{C}} 103.4,151.6 ; \delta_{\mathrm{H}} 4.79,4.91, \delta_{\mathrm{C}} 110.9,146.4\right)$. These observations suggested that 1 possessed a eudesmane framework with two hydroxy groups and two terminal double bonds [14-18]. From the HMBC experiment (Fig. 2), the angular methyl $\left(\mathrm{H}_{3}-14\right)$ correlated with $\mathrm{C}-1, \mathrm{C}-5, \mathrm{C}-9$ and $\mathrm{C}-10\left(\delta_{\mathrm{C}} 77.1,38.9,32.3\right.$ and 40.5 respectively), indicating that one hydroxyl group was linked at C-1. Similarly, the exomethylene protons $\left(\mathrm{H}_{2}-15\right)$ correlated with $\mathrm{C}-3$ and C-5 $\left(\delta_{\mathrm{C}} 70.4\right.$ and 38.9$)$, which clearly indicated that another hydroxyl group was located at C-3. In the NOE difference experiment, irradiation of $\mathrm{H}-1\left(\delta_{\mathrm{H}} 3.44\right)$ enhanced the resonances of $\mathrm{H}-3(0.81 \%), \mathrm{H}-2 \alpha(1.47 \%)$, and $\mathrm{H}-5(1.15 \%)$, but not $\mathrm{H}_{3}-14$, indicating that $\mathrm{H}-1, \mathrm{H}-3$ and $\mathrm{H}-5$ were all $\alpha$-oriented (assuming that $\mathrm{H}_{3}-14$ was $\beta$-oriented). Comparison of the carbon signal at C-7 $\left(\delta_{\mathrm{C}} 38.4\right)$ with that of ligucyperonol $\left(\delta_{\mathrm{C}} 45.1\right)$ [19] and $\beta$-dictyopterol $\left(\delta_{\mathrm{C}} 45.3\right)$ [20], suggested a $\beta$-orientation of H-7. Finally sesquiterpenoid 1 was elucidated as 7-epi-eudesm-4(15),11(13)-diene-1 $\beta, 3 \beta$-diol.

Table 1 NMR Spectroscopic Data (in $\mathrm{CDCl}_{3}, 400 \mathrm{MHz}$ ) of Sesquiterpenoids $\mathbf{1}$ and $\mathbf{2}$

\begin{tabular}{|c|c|c|c|c|}
\hline \multirow[t]{2}{*}{ No. } & \multicolumn{2}{|l|}{1} & \multicolumn{2}{|l|}{2} \\
\hline & ${ }^{1} \mathrm{H}(\delta)$ & ${ }^{13} \mathrm{C}(\delta)$ & ${ }^{1} \mathrm{H}(\delta)$ & ${ }^{13} \mathrm{C}(\delta)$ \\
\hline 1 & $3.44 \mathrm{dd}(12.0,4.4)$ & $77.1(\mathrm{~d})$ & $3.45 \mathrm{dd}(11.6,4.4)$ & $79.3(d)$ \\
\hline 2 & $2.23 \mathrm{~m}, 1.51 \mathrm{~m}$ & $40.8(\mathrm{t})$ & $1.82 \mathrm{~m}, 1.51 \mathrm{~m}$ & $31.4(\mathrm{t})$ \\
\hline 3 & $4.06 \mathrm{dd}(12.0,5.2)$ & $70.4(\mathrm{~d})$ & $2.32 \mathrm{~m}, 2.17 \mathrm{~m}$ & $34.3(\mathrm{t})$ \\
\hline 4 & & $151.6(\mathrm{~s})$ & & $149.3(\mathrm{~s})$ \\
\hline 5 & $1.73 \mathrm{~m}$ & $38.9(d)$ & $2.17 \mathrm{~m}$ & $41.8(d)$ \\
\hline 6 & $1.85 \mathrm{~m}, 1.67 \mathrm{~m}$ & $25.1(\mathrm{t})$ & $1.73 \mathrm{~m}, 1.63 \mathrm{~m}$ & $23.5(\mathrm{t})$ \\
\hline 7 & 2.45 brs & $38.4(d)$ & $1.68 \mathrm{~m}$ & $41.6(d)$ \\
\hline 8 & $1.88 \mathrm{~m}, 1.67 \mathrm{~m}$ & $22.9(\mathrm{t})$ & $1.78 \mathrm{~m}, 1.63 \mathrm{~m}$ & $20.8(t)$ \\
\hline 9 & $1.63 \mathrm{~m}, 1.37 \mathrm{~m}$ & $32.3(\mathrm{t})$ & $1.62 \mathrm{~m}$ & $34.0(\mathrm{t})$ \\
\hline 10 & & $40.5(\mathrm{~s})$ & & $39.6(\mathrm{~s})$ \\
\hline 11 & & $146.4(\mathrm{~s})$ & & $74.4(\mathrm{~s})$ \\
\hline 12 & $1.70 \mathrm{~s}$ & $22.2(\mathrm{q})$ & $1.27 \mathrm{~s}$ & $29.6(q)$ \\
\hline 13 & $\begin{array}{l}4.91 \mathrm{~d}(1.6) \\
4.79 \mathrm{~s}\end{array}$ & $110.9(\mathrm{t})$ & $1.26 \mathrm{~s}$ & $29.2(\mathrm{q})$ \\
\hline 14 & $0.74 \mathrm{~s}$ & $9.9(q)$ & $0.73 \mathrm{~s}$ & $11.1(\mathrm{q})$ \\
\hline 15 & $\begin{array}{l}5.11 \mathrm{~s}, \\
4.73 \mathrm{~d}(1.6)\end{array}$ & $103.4(t)$ & $\begin{array}{l}4.78 \mathrm{~d}(1.2) \\
4.54 \mathrm{~s}\end{array}$ & $106.8(\mathrm{t})$ \\
\hline
\end{tabular}

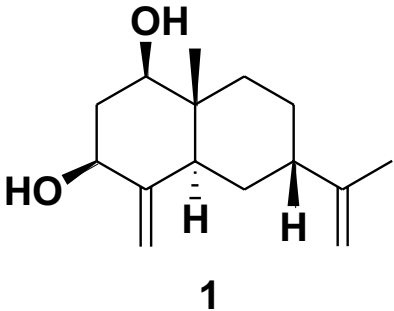

Fig. 1 Molecular structures of sesquiterpenoids $\mathbf{1}$ and $\mathbf{2}$

Sesquiterpenoid 2 was obtained as a white solid with $[\alpha]_{\mathrm{D}}^{20}+3.0(c 0.35$, acetone $)$, which indicated it maybe exist as a racemate. Its molecular formula was assigned as $\mathrm{C}_{15} \mathrm{H}_{26} \mathrm{O}_{2}$ on the basis of an ion at $\mathrm{m} / \mathrm{z} 261.1815$ $[\mathrm{M}+\mathrm{Na}]^{+}$(calcd for $\mathrm{C}_{15} \mathrm{H}_{26} \mathrm{O}_{2} \mathrm{Na}, 261.1825$ ) in the positive HRESIMS. Its IR absorptions at 3323 and $1645 \mathrm{~cm}^{-1}$ indicated the occurrence of hydroxy and olefinic functionalities, respectively. The ${ }^{1} \mathrm{H}$ and ${ }^{13} \mathrm{C}$ NMR data of 2 demonstrated three methyls $\left(\delta_{\mathrm{H}} 1.11,1.22,1.32 ; \delta_{\mathrm{C}} 11.1\right.$, $29.2,29.6)$, one oxymethine $\left(\delta_{\mathrm{H}} 3.45 ; \delta_{\mathrm{C}} 79.3\right)$, one oxygenated tertiary carbon $\left(\delta_{\mathrm{C}} 74.4\right)$, and one terminal double bond $\left(\delta_{\mathrm{H}} 4.54,4.78 ; \delta_{\mathrm{C}} 106.8,149.3\right)$. These observations indicated 2 as an eudesmane sesquiterpenoid possessing two hydroxy groups and one terminal double bond [14-18]. Furthermore, its planer structure was constructed via HMBC experiment as shown in Fig. 2. From the NOE difference experiment, irradiation of $\mathrm{H}-1\left(\delta_{\mathrm{H}} 3.45\right)$ 


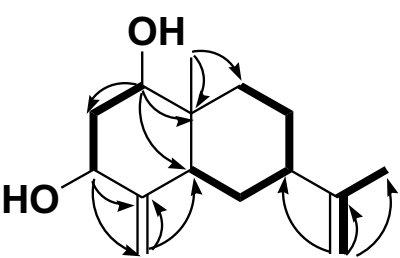

1

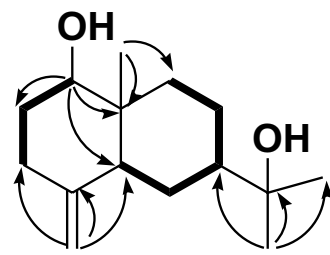

2
Fig. 2 Key COSY $(\mathrm{H} \rightarrow \mathrm{H}), \mathrm{HMBC}(\mathrm{H} \rightarrow \mathrm{C})$ correlations of $\mathbf{1}$ and $\mathbf{2}$

enhanced the signals of H-3 $\alpha(1.47 \%)$ and $\mathrm{H}-5$ (1.11\%) indicating that $\mathrm{H}-1$ and $\mathrm{H}-5$ was $\alpha$-oriented. The chemical shifts of $\mathrm{C}-1 / 2 / 10$ of compound $8\left(\delta_{\mathrm{C}} 79.3 / 31.4 / 39.6\right.$ in $\mathrm{CDCl}_{3}$ ), which were similar to those of $\beta$-dictyopterol $\left(\delta_{\mathrm{C}} 79.3 / 31.5 / 40.2\right.$ in $\left.\mathrm{CDCl}_{3}\right)$ [20], were used to determine the $\beta$-oriented $\mathrm{Me}-14$. The $\beta$-orientation of $\mathrm{H}-7$ was deduced from dramatic differences in chemical shifts of C-5/7/9 in compound $8\left(\delta_{\mathrm{C}} 41.8 / 41.6 / 34.0\right.$ in $\left.\mathrm{CDCl}_{3}\right)$ and $1 \beta$-hydroxy- $\beta$-eudesmol $\left(\delta_{\mathrm{C}} 47.5 / 48.9 / 36.9\right.$ in $\mathrm{CDCl}_{3}$ ) [21]. Thus, sesquiterpenoid 2 was established as 7 -epi-1 $\beta$-hydroxy- $\beta$-eudesmol.

\section{Experimental Section}

\subsection{General}

Optical rotations were measured on a Perkin-Elmer model 341 polarimeter with a $1 \mathrm{dm}$ cell. IR spectra were obtained on a Nicolet NEXUS 670 FT-IR spectrometer. NMR spectra were recorded on a Bruker AVANCE Ш-400 spectrometer. Chemical shifts are given as $\delta$ (ppm) using TMS as internal standard. HRESIMS were carried out on a Bruker APEX II mass spectrometer. Sephadex LH-20 (GE Healthcare Bio-science AB, Sweden), $\mathrm{C}_{18}$ reversedphase silica gel (YMC, ODS-A, AA120S50), Silica gel (200-300 mesh, Qingdao Marine Chemical factory, Qingdao, China.) were used for column chromatography (CC). TLC using silica $\mathrm{GF}_{254}(10-40 \mu \mathrm{m})$ was detected at $254 \mathrm{~nm}$ and spots were visualized by spraying with $5 \%$ $\mathrm{H}_{2} \mathrm{SO}_{4}$ in EtOH (v/v) followed by heating.

\subsection{Plant Material}

The flowers of $C$. indicum was purchased from Huanghe Medicinal Material Market in Gansu in 2009 and identified by Associate Prof. H.Y. Qi of CAS Key Laboratory of Chemistry of Northwestern Plant Resources in LICP, where a voucher specimen (No. ZY2009C001) was deposited.

\subsection{Extraction and Isolation}

The air-dried flowers of $C$. indicum $(2.0 \mathrm{~kg})$ were pulverized and extracted with $95 \% \mathrm{EtOH}(3 \times 5 \mathrm{~L})$ at $50{ }^{\circ} \mathrm{C}$ for $3 \mathrm{~h}$ each time. The combined extracts were evaporated to dryness under reduced pressure. The resulting residue was mixed with $\mathrm{H}_{2} \mathrm{O}(1.5 \mathrm{~L})$ to form a suspension and partitioned successively with petroleum ether (PE), EtOAc, and $n$-BuOH. The PE-soluble part $(60 \mathrm{~g})$ was subjected to silica gel CC with a gradient system of PE-EtOAc (60:1, 30:1, 15:1, 10:1, $7: 1,5: 1,3: 1$ and $1: 1)$ to afford eight fractions (A-H) based on TLC analysis. Fractions F-G was purified over a column of Sephadex LH-20 using $\mathrm{CHCl}_{3}-\mathrm{MeOH}(2: 1)$ to give tho sub-fractions (F1 and G1) without pigments. Sub-fraction $\mathrm{F} 1$ was separated by silica gel CC eluted repeatedly with $\mathrm{CHCl}_{3}$-EtOAc (25:1, 15:1 and 10:1), PE-EtOAc (10:1), $\mathrm{CHCl}_{3}-\mathrm{Me}_{2} \mathrm{CO}$ (15:1), and a column of $\mathrm{C}_{18}$ reversed-phase silica gel $\left(\mathrm{MeOH}-\mathrm{H}_{2} \mathrm{O}, 70: 30,60: 40\right)$, to give $2(12.3 \mathrm{mg})$. Sub-fraction G1A was repeated purified by silica gel eluted with $\mathrm{CHCl}_{3}-\mathrm{Me}_{2} \mathrm{CO}$ (10:1) and $\mathrm{PE}-\mathrm{Me}_{2} \mathrm{CO}$ (8:1.5), and then over a $\mathrm{C}_{18}$ reversed-phase silica gel eluted by $\left(\mathrm{MeOH}-\mathrm{H}_{2} \mathrm{O}\right.$, 60:40, 50:50) to yield $\mathbf{1}(16.1 \mathrm{mg})$.

\subsection{Characteristic Data of Compounds}

7-epi-eudesm-4(15),11(13)-diene-1 $\beta, 3 \beta$-diol (1): White solid; $[\alpha]_{\mathrm{D}}^{20}+5.0(c 0.2$, acetone); IR $(\mathrm{KBr}) \nu$ max $: 3384$, 2924, 1654, 1458, 1064, $803 \mathrm{~cm}^{-1} ;{ }^{1} \mathrm{H}$ and ${ }^{13} \mathrm{C}$ NMR data, Table 1; HRESIMS: $m / z 219.1750\left[\mathrm{M}-\mathrm{H}_{2} \mathrm{O}+\mathrm{H}\right]^{+}$(calcd for $\mathrm{C}_{15} \mathrm{H}_{23} \mathrm{O}, 219.1743$ ).

7-epi-1 $\beta$-hydroxy- $\beta$-eudesmol (2): White solid; $[\alpha]_{\mathrm{D}}^{20}+3.0$ (c 0.35, acetone); IR (KBr) $\nu_{\text {max }}: 3323,2970,1645,1455$, 1034, $884 \mathrm{~cm}^{-1}$; ${ }^{1} \mathrm{H}$ and ${ }^{13} \mathrm{C}$ NMR data, Table 1; HRESIMS: $\mathrm{m} / \mathrm{z} 261.1815[\mathrm{M}+\mathrm{Na}]^{+}$(calcd for $\mathrm{C}_{15} \mathrm{H}_{26} \mathrm{O}_{2} \mathrm{Na}, 261.1825$ ).

Acknowledgements This work was financially supported by National Natural Science Foundation of China (Nos. 81673325, 81711540311, and 21705156), the International Partnership Program of CAS (No. 153631KYSB20160004), Gansu Province Key International S\&T Cooperation Project (No. 18YF1WA127), and CAS Pioneer Hundred Talents Program.

\section{Compliance with Ethical Standards}

Conflict of interest The authors declare no competing financial interest.

Open Access This article is distributed under the terms of the Creative Commons Attribution 4.0 International License (http://creativeco mmons.org/licenses/by/4.0/), which permits unrestricted use, distribution, and reproduction in any medium, provided you give appropriate credit to the original author(s) and the source, provide a link to the Creative Commons license, and indicate if changes were made. 


\section{References}

1. L.-L. Liu, T.K.Q. Ha, W. Ha, W.K. Oh, J.-L. Yang, Y.-P. Shi, J. Nat. Prod. 80, 298-307 (2017)

2. Q.X. Wu, Y.P. Shi, Z.J. Jia, Nat. Prod. Rep. 23, 699-734 (2006)

3. B.M. Fraga, Nat. Prod. Rep. 30, 1226-1264 (2013)

4. B.M. Fraga, Nat. Prod. Rep. 29, 1334-1366 (2012)

5. B.M. Fraga, Nat. Prod. Rep. 28, 1580-1610 (2011)

6. B.M. Fraga, Nat. Prod. Rep. 27, 1681-1708 (2010)

7. B.M. Fraga, Nat. Prod. Rep. 26, 1125-1155 (2009)

8. B.M. Fraga, Nat. Prod. Rep. 25, 1180-1209 (2008)

9. B.M. Fraga, Nat. Prod. Rep. 24, 1350-1381 (2007)

10. B.M. Fraga, Nat. Prod. Rep. 23, 943-972 (2006)

11. B.M. Fraga, Nat. Prod. Rep. 22, 465-486 (2005)

12. Chinese Pharmacopoeia Commission, Chinese Pharmacopoeia (China Medical Science Press, Beijing, 2015), p. 33
13. Z.M. Feng, S. Song, P.F. Xia, J.S. Jiang, P.C. Zhang, Helv. Chim. Acta 92, 1823-1828 (2009)

14. H.L. Jiang, W. Ha, J.L. Yang, Y.P. Shi, Phytochemistry Lett 17, 1-5 (2016)

15. J.L. Yang, Y.M. Zhao, Y.P. Shi, Nat. Prod. Bioprospect. 6, 211216 (2016)

16. X.Y. Xie, R. Wang, Y.P. Shi, Planta Med. 78, 1010-1014 (2012)

17. J.L. Yang, Y.P. Shi, Phytochemistry 76, 124-132 (2012)

18. J.L. Yang, R. Wang, L.L. Liu, Y.P. Shi, Planta Med. 77, 362-367 (2011)

19. K. Naya, T. Okayama, M. Fujiwara, M. Nakata, T. Ohtsuka, S. Kurio, Bull. Chem. Soc. Jpn 63, 2239-2245 (1990)

20. L.H. Hu, Z.L. Chen, Phytochemistry 44, 1287-1290 (1997)

21. H.I. El-Askary, M.R. Meselhy, A.M. Galal, Molecules 8, 670-677 (2003) 